\title{
Changes in the Spatial Concentration of Employment across U.S. Counties: A Sectoral Analysis 1972-2000*
}

\author{
Klaus Desmet \\ Universidad Carlos III de Madrid \\ and CEPR
}

\author{
Marcel Fafchamps \\ University of Oxford
}

June 2004

\begin{abstract}
Using U.S. county data, we estimate employment growth equations to analyze how the spatial distribution of jobs has changed between 1972 and 2000. We find that total employment has become increasingly concentrated. This aggregate picture hides important sectoral differences though: whereas non-service employment has been spreading out, service jobs have clustered in areas of high aggregate employment. By controlling for employment at different distances, we explicitly take into account the spatial dimension. This allows us to conclude that the spreading out of non-service jobs has benefitted counties 20 to $70 \mathrm{~km}$ away from large agglomerations, whereas the concentration of services has come at the expense of jobs in the surrounding 20 kilometers.
\end{abstract}

JEL Classification Codes: R11, R12.

Keywords: Economic geography; spatial economics; U.S. counties.

\footnotetext{
*Desmet: Department of Economics, Universidad Carlos III de Madrid, 28903 Getafe (Madrid), Spain. E-mail: desmet@eco.uc3m.es; Fafchamps: CSAE, Department of Economics, University of Oxford, Manor Road, Oxford OX1 3UQ, United Kingdom. E-mail: marcel.fafchamps@economics.oxford.ac.uk. We thank the editor, three anonymous referees, and seminar participants at the University of Alicante, CEMFI, the European Trade Study Group, and the European Meetings of the Econometric Society in Lausanne. Financial aid from the Spanish Ministry of Science and Technology (BEC2002-03715), the Ramón and Cajal Program, and the Comunidad de Madrid (06/0096/2003) is gratefully acknowledged.
} 


\section{Introduction}

Peaks of high activity with lots of 'empty' space in between are a striking feature of the economic landscape. Starting with Marshall (1890), this phenomenon has been explained by the interaction of agglomeration and congestion forces. Positive externalities

- knowledge spillovers, thick labor markets, and forward and backward linkages — lead to agglomeration; negative externalities — rising commuting costs and increasing land rents - cause congestion and put a cap on the size of clusters. ${ }^{1}$ Agglomeration and congestion forces may evolve over time, affecting the economy's spatial distribution.

This paper analyzes how the concentration of employment across U.S. counties has changed between 1972 and 2000. To do so, we estimate an employment growth equation, controlling for both geographical features and initial employment. At the aggregate level we find that employment has become more concentrated. However, behind the veil of aggregation lie important sectoral differences. Employment in non-service sectors, such as manufacturing, has been spreading out. In the service sectors the opposite has been happening: jobs have become increasingly concentrated. This suggests that services rather than manufacturing — are driving the aggregate employment dynamics. This should not come as a surprise, as the U.S. is a service economy.

By controlling for employment at different distances from the county under consideration, we are able to estimate how the deconcentration of manufacturing and the concentration of services have affected the hinterland. In service sectors growth was higher in centers of high aggregate employment, but lower in areas 5 to 20 kilometers away; in non-service sectors, growth was lower in aggregate employment centers, but higher in areas 20 to 70 kilometers away. This suggests that service employment has been concentrating in centers of high economic activity at the cost of service jobs in the hinterland. Non-service sectors, instead, has moved out of economic centers to less congested areas 20 to 70 kilometers away.

The different behavior of non-service and service sectors is consistent with a num-

\footnotetext{
${ }^{1}$ This argument underlies much of the work in urban economics (Mills, 1967; Henderson, 1974) and economic geography (Fujita, Krugman and Venables, 1999).
} 
ber of different explanations. One candidate is falling transport costs. Due do their nontradeable nature, services have traditionally been spread out. The drop in transport costs is now allowing them to agglomerate. ${ }^{2}$ Manufacturing, however, already became highly concentrated during the 19th century (Kim, 1995; Glaeser, 1998); the more recent fall in transport costs has been weakening the benefits from agglomeration, leading manufacturing activity to spread out. The different job patterns across non-service and service sectors may also be due to technological change. Carlino (1985), for instance, argues that the splitting up of the production process into different stages has allowed manufacturing firms to relocate certain activities to less dense areas. As for the rising concentration of services in cities, Kolko (1999) suggests that high tech services are experiencing an increasing need to be close to specialized workers. Another reason that may explain the spatial differences across sectors is the land intensity of production (Glaeser and Kahn, 2001). As overall employment grows, and land prices rise, more land intensive activities, such as manufacturing, are being replaced by less land intensive activities, such as services.

Our paper is closely related to the urban economics literature. The results fit the picture of cities losing manufacturing employment, and becoming service centers (Glaeser, 1998). For example, textiles and publishing moved out of New York City during the 1970s and the 1980s, leaving it to be mainly a financial center (Glaeser and Kahn, 2001). However, our findings collide with the stylized facts of urban economics in two respects. First, while it has been documented that metropolitan employment is deconcentrating (Chatterjee and Carlino, 2001), we find the opposite is happening at the county level. Second, studies on metropolitan areas suggest that suburbanization has been occurring across all sectors, including services (Macauley, 1985). Instead, our results indicate that deconcentration is limited to the nonservice part of the economy.

Clearly, some of these differences may stem from our focus on counties, rather than cities. In addition to leading to certain novel results, looking at counties has the

\footnotetext{
${ }^{2}$ Not everyone agrees that transport costs in services have decreased. Glaeser (1998), for instance, argues that though the cost of moving goods has gone down, the cost of moving people - as measured by the opportunity cost of time - has gone up.
} 
further advantage of avoiding selection bias, ${ }^{3}$ increasing the number of observations, and augmenting cross-sectional variation. Though there has been similar work on France (Combes, 2000), studies on changes in spatial concentration across the entire U.S. have generally focused on larger geographical units: Kim (1995), for instance, analyzes census regions, whereas Dumais, Ellison and Glaeser (2002) look at U.S. states. Our finer level of disaggregation is preferable because static estimates of externalities suggest they have limited geographical reach. Ellison and Glaeser (1997), for instance, found that spillovers are stronger within counties than within states. Micro-based studies have come to similar conclusions (Jaffe, Trajtenberg and Henderson, 1993; Wallsten, 2001).

Returning to Combes (2000), many of our results on U.S. counties reinforce his findings on the differences between service and non-service sectors in France. As in Combes, we distinguish between localization economies, benefits which derive from being located close to other firms in the same industry, and urbanization economies, associated with closeness to overall economic activity. This ties in with previous work by Glaeser, Kallal, Scheinkman and Shleifer (1992) and Henderson, Kuncoro and Turner (1995). However, our paper differs from Combes in that it explicitly takes into account the spatial dimension of agglomeration economies.

Following up on that last point, studies based on metropolitan data are forced to implicitly assume that cities are islands, where the hinterland does not matter. However, when using county data covering the entire U.S. there is no need to place artificial bounds on agglomeration economies. Our paper therefore takes the view that a county's employment growth is not only affected by the county under consideration, but also by all 'nearby' counties, where we let the data tell us what 'nearby' means.

Of course taking into account the spatial aspect of externalities is hardly a novel idea: nearly half a century ago Harris (1954) pioneered the notion of market potential - a weighted average of purchasing power where the weights decay with distance to explain the location of manufacturing in the United States. However, estimating a

\footnotetext{
${ }^{3}$ As pointed out by Beeson, DeJong and Troesken (2001), focusing on cities, rather than counties, introduces a bias by only considering those place which experienced successful growth in the past.
} 
simple spatial decay function, as in Harris (1954), will not do for our purposes. Since the dependent variable is the growth of employment, rather than the level, the effect of distance may be more complex. For instance, we find that service growth was greater in high employment counties and smaller in the immediate hinterland. In our estimated equation this shows up as growth in services being positively affected by employment in the own county; negatively affected by employment in close-by counties; and not affected by employment in more far-off counties. This is a third-degree polynomial, rather than a simple decay function. Assuming any specific functional form a priori is thus unwarranted; instead, we use a semi-parametric approach which limits itself to imposing some smoothness properties.

\section{Theoretical framework}

\subsection{A benchmark model with sectoral and aggregate externalities}

In a constant returns to scale world without spatial externalities, perfect mobility of capital and labor tends to bring about an even distribution of economic activity across space, since the use of land leads to decreasing returns to the mobile factors of production. Some clustering does occur, though, once particular geographical features are taken into account. Farmers, for instance, locate where land is more fertile, and mining companies locate next to mineral deposits. Geographical features may also affect location through people's preferences: if workers like to live at the beach or in a warm climate, firms will follow (Rappoport and Sachs, 2003).

Further clustering arises when spatial externalities are introduced (Marshall, 1890; Mills, 1967; Henderson, 1974; Rodríguez Clare, 1996; Fafchamps, 1997; Fujita, Krugman and Venables, 1999). These positive feedback mechanisms reinforce the initial patterns of specialization. This implies a role for path dependence - and thus also for random events

— in determining the spatial distribution of economic activity. Whether initial location is driven by geographical features or by random events, clustering creates advantages of its own, irrespective of initial conditions. Although originally people migrated to California in search of gold, path dependence (and the sun) have kept them there, even if gold has 
all but disappeared.

These insights translate into the following equation:

$$
\log L_{2000}^{i s}=\alpha^{s}+\left(1+\beta^{s}\right) \log L_{1972}^{i s}+\delta^{s} H^{i}+\varepsilon^{i s}
$$

where $\alpha^{s}$ is a sector-specific constant; $L^{i s}$ is employment in county $i$ and sector $s ; H^{i}$ is a vector of geographical features of county $i$, such as being located at the coast or a waterway; and $\varepsilon^{i s}$ is an error term.

The above equation only considers sector-specific externalities. However, some spatial effects — such as market potential and land prices — come from aggregate externalities. The literature has long distinguished between these two types of externalities: localization economies, based on the proximity to other firms in the same sector, and urbanization economies, coming from overall economic activity or diversity.

To distinguish between urbanization and localization economies in our simple model, take the above equation, and replace $\left(L_{1972}^{i s}\right)^{1+\beta^{s}}$ with $\left(L_{1972}^{i s}\right)^{1+\beta^{s}}\left(L_{1972}^{i}\right)^{\gamma^{s}-\beta^{s}}$. We are thus considering total and sectoral employment to be imperfectly substitutable in their agglomeration and congestion effects. Now re-write $\left(L_{1972}^{i s}\right)^{1+\beta^{s}}\left(L_{1972}^{i}\right)^{\gamma^{s}-\beta^{s}}$ as $\left(L_{1972}^{i s}\right)\left(\frac{L_{1972}^{i s}}{L_{1972}^{i}}\right)^{\beta^{s}}\left(L_{1972}^{i}\right)^{\gamma^{s}}$, and take logs. This gives us an expression for sectoral employment growth:

$$
\log L_{2000}^{i s}-\log L_{1972}^{i s}=\alpha^{s}+\beta^{s} \log \frac{L_{1972}^{i s}}{L_{1972}^{i}}+\gamma^{s} \log L_{1972}^{i}+\delta^{s} H^{i}+\varepsilon^{i s}
$$

In the empirical section we will refer to (1) as Model 1. When estimating the model, we account for the possibility that disturbances $\varepsilon^{i s}$ are correlated across space. To this effect, we correct standard errors using the method proposed by Conley (1999), which is essentially an extension of the Newey-West correction of standard errors in time series, itself based on White robust standard errors. The advantage of this method is that it does not impose any extraneous structure on the shape of spatial autocorrelation.

To interpret the coefficients in equation (1), assume for now that capital and labor are sufficiently mobile across counties so that the economy is in steady state at all times. ${ }^{4}$

\footnotetext{
${ }^{4}$ This allows us to abstract from transitional dynamics, familiar from the empirical growth literature; we will return to this alternative interpretation later.
} 
In that case, if conditions did not change between 1972 and 2000, the spatial distribution of employment would not have changed either, so that $\alpha^{s}=\beta^{s}=\gamma^{s}=\delta^{s}=0$.

But of course changes did occur over those three decades. Our simple theoretical framework allows us to distinguish between five different types of changes - corresponding to the five terms in (1) — that may have affected the spatial distribution of employment: weakening or strengthening localization economies; weakening or strengthening urbanization economies; changes in the role of geographical features; sector-specific changes; and random county-specific sectoral shocks. We now look in turn at each one of these possibilities to see how they would show up in equation (1).

If localization economies weakened, $\beta^{s}$ would be negative, reflecting sectoral employment having become more equally spread across counties. Likewise, if localization economies strengthened, $\beta^{s}$ would be positive, suggesting further clustering of sectoral employment. For instance, if the drop in transport costs reduced the benefit from specialized firms clustering together, $\beta^{s}$ should be negative. Or if the increasing complexity of technologies made locating close to workers more important, $\beta^{s}$ should be positive (Kolko, 1999). An analogous argument can be made for urbanization economies. For instance, if online banking reduced the need to locate in large agglomerations, $\gamma^{s}$ would be negative.

An example of the changing role of geographical features could be the increasing relevance of coasts, showing up as a positive coefficient $\delta^{s}$ for coastal areas (Rappaport and Sachs, 2003). Another example would be the increased attraction of firms to warm weather, giving a positive coefficient $\delta^{s}$ to being located in the South. This phenomenon could be explained by workers in warm weather having become more productive, following the introduction of air conditioning. Or shifting preferences could have played a role: people have been moving South and West, with firms following suit (Glaeser and Shapiro, 2001).

As for sector-specific shocks, we could think of the oil shocks of the 1970s having had a negative effect on automobile producers, and a positive effect on the oil industry: this would show up in a negative $\alpha^{s}$ for the automobile industry and a positive $\alpha^{s}$ for the 
oil industry. Another possibility would be that the sector-specific coefficient $\alpha^{s}$ picked up changes in comparative advantage, epitomized by the rise of services and the demise of manufacturing.

Finally, county-specific sectoral shocks may also have affected the spatial distribution of employment. For instance, if Los Angeles residents voted a resolution on restricting industrial pollution, this would give us a negative $\varepsilon^{i s}$ for contaminating activities in Los Angeles county.

As mentioned before, our interpretation of (1) is to say that changes in underlying conditions make the economy move from one steady state or equilibrium in 1972 to another equilibrium in 2000. An alternative reading, in line with the empirical growth literature, would be to take a transitional dynamics interpretation, where the economy moves to a steady state over time (Mankiw, Romer and Weil, 1992; Barro and Sala-iMartin, 1995). To see the difference in interpretation, focus on the coefficients $\beta^{s}$ and $\gamma^{s}$. Both approaches would concur that localization and urbanization externalities determine the spatial distribution of employment. However, according to the transitional dynamics view the spatial distribution would still be changing because the economy has not yet converged to steady state. In contrast, in our interpretation the economy starts off already in steady state. Any changes in the distribution are then due to changes in the strength of spatial externalities.

Given the focus on counties, our interpretation seems appropriate: contrary to larger units of analysis, such as states or countries, mobility of capital and labor is high across U.S. counties, so that arguably the economy is never too far away from its steady state or equilibrium. In other settings a different interpretation may be warranted though. Combes (2000), for instance, studies local job growth in France. As he points out, labor mobility across French zones d'emploi is limited, so that taking a transitional dynamics approach may be more reasonable. One further difference with Combes (2000) is worth pointing out: we consider urbanization economies as coming from aggregate economic activity. Another commonly held view emphasizes the diversity of activities, rather than their overall size. But given that we are using a data set with only 13 sectors, calculating 
diversity indices makes little sense.

Note that localization and urbanization economies need not be static in nature. Their dynamic counterparts are known as Marshall-Arrow-Romer (MAR) and Jacobs externalities. Glaeser et al. (1992) and Henderson et al. (1995) have studied the presence of such externalities using city data. Although their estimating equations are similar to ours, their interpretation is slightly different. Whereas we would view a positive $\gamma^{s}$ as a sign of strengthening urbanization economies, they would interpret it as evidence of dynamic externalities. The difference lies in the fact that dynamic externalities allow for growth in steady state, whereas static externalities do not. Discriminating between both interpretations is not obvious though.

\section{$2.2 \quad$ Including spatial spillovers}

Spatial externalities do not stop at county borders; agglomeration economies and congestion effects spill over into neighboring locations (Harris, 1954; Fujita and Ogawa, 1982). A rural county in the vicinity of the San Francisco Bay Area still benefits from its proximity to Silicon Valley, whereas a rural county in the middle of nowhere does not. When high-tech firms move out of the West Bay to avoid the Valley's increasing congestion, they may prefer the close-by, less congested East Bay over far-off locations.

To take into account the effect of neighboring locations, we re-write equation (1) in the following way:

$\log L_{2000}^{i s}-\log L_{1972}^{i s}=\alpha^{s}+\int_{0}^{\infty} \beta^{s}(m) \log \frac{L_{1972}^{i s}(m)}{L_{1972}^{i}(m)} d m+\int_{0}^{\infty} \gamma^{s}(m) \log L_{1972}^{i}(m) d m+\delta^{s} H^{i}+\varepsilon^{i s}$ where $L^{i s}(m)$ denotes sectoral employment in counties situated $m$ kilometers from county $i$.

If the dependent variable were the level of employment, it would be natural to model $\beta^{s}($.$) and \gamma^{s}($.$) as simple decay functions. However, given that the dependent$ variable is the growth of employment, we have no strong prior about the shapes of $\beta^{s}($. and $\gamma^{s}($.$) . For instance, suppose weakening agglomeration economies encourage firms to$ spread out. Economic clusters lose employment, whereas areas close to those clusters gain employment; this would show up as $\gamma^{s}($.$) starting off with a negative sign, then turning$ 
positive at relatively short distances, before decaying to zero at longer distances. It is therefore important not to put any a priori restriction on the shapes of $\beta^{s}($.$) and \gamma^{s}($.$) .$ The same is true for the pattern of spatial autocorrelation in the disturbances.

For estimation purposes we replace the continuous functions $\beta^{s}($.$) and \gamma^{s}($.$) with$ discrete approximations and obtain the following regression:

$\log L_{2000}^{i s}-\log L_{1972}^{i s}=\alpha^{s}+\sum_{m=0}^{D} \beta^{s}(m) \log \frac{L_{1972}^{i s}(m)}{L_{1972}^{i}(m)}+\sum_{m=0}^{D} \gamma^{s}(m) \log L_{1972}^{i}(m)+\delta^{s} H^{i}+\varepsilon^{i s}$

where each value of index $m$ now represents a distance interval from county $i-$ say, from 0 to $5 \mathrm{~km}$, from 5 to $10 \mathrm{~km}$, etc. - and $D$ is the number of intervals. There is no natural distance beyond which agglomeration and congestion effects die out; however, as will be shown, the effect of counties more than 100 kilometers away is negligible. In the empirical section equation (2) will be referred to as Model 2. It is our preferred specification.

To improve efficiency, we impose a certain smoothness on functions $\beta^{s}($.$) and \gamma^{s}($. by adopting a roughness penalty approach. This method, pioneered by Good and Gaskins (1971) and Silverman (1982), prevents the slopes of $\beta^{s}($.$) and \gamma^{s}($.$) from changing too$ rapidly by adding a penalty function to the standard least square criterion. For instance, in the case of $\gamma^{s}($.$) , this penalty function is:$

$$
\sum_{m=1}^{D-1} \lambda^{2}\left[\left(\gamma^{s}(m+1)-\gamma^{s}(m)\right)-\left(\gamma^{s}(m)-\gamma^{s}(m-1)\right)\right]^{2}
$$

The parameter $\lambda$ determines the severity of the penalty for a given difference in 'neighboring' coefficients; a greater $\lambda$ implies a higher degree of smoothing. When the estimating function is a likelihood function instead of least squares, Silverman $(1982,1984)$ has shown that the above yields a kernel estimator of $\gamma^{s}(.){ }^{5}$ With the roughness penalty correction, we should in principle bootstrap standard errors. This is not feasible here because computing the Conley correction for spatially autocorrelated errors takes over one

\footnotetext{
${ }^{5}$ In practice, the roughness penalty correction can be implemented by adding $D-2$ artificial observations at the end of the sample. If $T$ is the number of true observations, the artificial observations go from $n=T+1$ to $n=T+D-2$. For artificial observation $n$ the dependent variable and all regressors are 0 , except for $L_{1972}^{i}(n-T-1)=\lambda, L_{1972}^{i}(n-T)=-2 \lambda$, and $L_{1972}^{i}(n-T+1)=\lambda$. Applying the standard OLS formula to the modified sample yields the roughness penalty estimator.
} 
hour per regression; bootstrapping them would take weeks, if not months, of computer time. However, comparison between OLS standard errors and bootstrapped standard errors (without the Conley correction) reveal very little difference between the two. This is because the roughness penalty correction does not affect estimated coefficients much. We can therefore reasonably assume that the bias introduced by not bootstrapping Conley standard errors is negligible.

\section{The data}

County-level sectoral employment data come from the Regional Economic Information System (REIS) compiled by the U.S. Bureau of Economic Analysis (BEA). We use employment data for 1972 and 2000 in thirteen sectors, covering the entire economy: farming; agricultural services; mining; construction; manufacturing; transportation and utilities; wholesale; retail; FIRE (finance, insurance and real estate); other services; federal government; military; and state and local government. After dropping Alaska and Hawaii from the analysis ${ }^{6}$ we are left with 3092 counties. Sectoral employment data are missing for some counties, either because they are unavailable or because they are not disclosed. ${ }^{7}$

Between 1972 and 2000 employment in the contiguous United States grew on average $2 \%$ a year (Table 1). Growth was fastest in agricultural services and in 'other services'. Farming and the military, on the contrary, experienced a reduction in absolute employment levels, whereas manufacturing stagnated. A similar picture emerges when considering employment shares; farming and manufacturing shrunk dramatically, with 'other services' filling the gap.

[Insert Table 1 here]

\footnotetext{
${ }^{6}$ Alaska and Hawaii are quite different from the contiguous U.S. both in terms of distance to the mainland and in terms of geography (Hawaii is made up of islands; Alaska is close to the polar circle). The mobility of capital and labor is probably less with the rest of the economy than among contiguous US states and we expect model parameters to be different. Pooling them with continguous US is thus not appropriate.

${ }^{7}$ For some counties sectoral employment is not revealed in order not to violate employer confidentiality. For other counties sectoral employment is simply reported as 'less than 10'; in those cases we set employment equal to 5 .
} 
Data on county area, latitude, and longitude come from the U.S. Geological Survey (USGS). Counties are assumed to be centered at their county seat. The average county size is 2491 square kilometers, corresponding to an average diameter of approximately 50 kilometers (30 miles). ${ }^{8}$ Counties vary considerably in size, however: the coefficient of variation of county area is 1.36 . Western counties in particular tend to be larger than their eastern counterparts. Distance $d_{i j}$ between counties $i$ and $j$ is calculated 'as the crow flies' using the following formula:

$$
\left.d_{i j}=\frac{10000}{90} \arccos _{\sin l a t_{i} \sin l a t_{j}}+\cos l a t_{i} \cos l a t_{j} \cos \left(l_{\text {long }}-l_{j} \text { lon }_{i}\right)\right]
$$

where lat is the latitude and long is the longitude of the county seat in degrees. This is a reasonable approximation of transportation distance, given the density of the U.S. road and rail network.

Distance $d_{i j}$ is used to construct the employment variables $L^{i s}(m)$. We divide distance from county $i$ into $5 \mathrm{~km}$ intervals: $0-5 \mathrm{~km}, 5-10 \mathrm{~km}, 10-15 \mathrm{~km}$, etc. We go to a maximum of 100 kilometers, since estimation results suggest that spatial effects die out beyond that distance. ${ }^{9}$ For each distance interval (or 'donut') we sum the sectoral employment of all counties (for which the county seat is) located in that particular 'donut'. This procedure, performed with the help of a Fortran program, yields a vector of 20 employment variables $L^{i s}(m)$, in addition to the county's own employment. In case there is no county seat in a given 'donut', $L^{i s}(m)$ is set to zero. This normalization is equivalent to setting to zero the externalities that affect 'island' counties, that is, counties with no neighbors.

By construction, county seats located in large counties are less likely to be close to other county seats. To correct for this phenomenon, county area is included as a separate regressor. ${ }^{10}$ We also control for being on an 'edge' — such as an ocean, lake or border — since this may affect location. For instance, if ocean shipping becomes

\footnotetext{
${ }^{8}$ This approximation obviously underestimates the actual diameter, since counties are not perfect circles. It is nevertheless useful as a ballpark figure.

${ }^{9}$ This ignores the possibility of optimal spacing between cities (Isard, 1956), an issue that would require another methodology.

${ }^{10}$ Instead of assuming that economic activity is concentrated at the county seat, we could also adopt
} 
cheaper, counties on the coasts might benefit; if tariffs come down, counties on the U.S. border may attract more jobs. We construct separate 'edge' dummies for: the Atlantic ocean; the Pacific ocean; the Great Lakes; the gulf of Mexico; the Mexican border; and the Canadian border. Information of proximity to borders and water was compiled from detailed maps provided by the American Automobile Association (AAA).

Changes in location have also been affected by general trends, such as the tendency for jobs to move to the West and the South (Blanchard and Katz, 1992; Mills and Hamilton, 1994; Glaeser, Scheinkman and Shleifer, 1995; Hanson, 1998). Latitude and longitude are therefore included as regressors. Finally, given that economic activity in the U.S. is concentrated on the Atlantic and the Pacific seaboards, we consider the possibility that the coasts are subject to different employment trends (Rappaport and Sachs, 2003). We therefore add dummies for counties located in states on the East coast or the West coast.

\section{Empirical results}

\subsection{Sector-specific and aggregate externalities}

Our starting point is Model 1, which regresses annual sectoral employment growth on the initial sectoral employment share and on initial aggregate employment, without taking into account spatial spillovers. In Table 2 we present OLS point estimates of regression (1), and we report t-values based on spatially corrected standard errors. The dependent variable is of the form $\frac{\log L_{2000}^{i s}-\log L_{1972}^{i s}}{28}$, so that all coefficients can be interpreted in terms of annual growth rates. ${ }^{11}$

\footnotetext{
the view that economic activity is evenly spread across each county. In that case we would regress on employment density (as in Ciccone and Hall, 1996), rather than on employment level. Experimenting with this alternative did not improve our results though.

${ }^{11}$ One practical issue that arises in calculating the dependent variable is what to do with zero observations. Omitting counties with zero initial employment and no employment growth would bias results in favor of convergence: after all, if convergence forces were at play, counties with no initial employment should grow fastest. To avoid this bias, we replace all 0 employment by 1 . This is akin to assuming that at least one person in each county performs one of the 13 broadly defined functions corresponding to each sector. It implies that counties with no employment in both census years show up with zero employment growth, which is the correct interpretation.
} 
[Insert Table 2 here]

Two results stand out. First, all sectors have been moving out of sector-specific clusters, as can be seen from the negative coefficients on initial sectoral shares. Second, there is a sharp contrast between non-service and service sectors when it comes to urbanization economies: whereas non-service sectors have been leaving areas of high aggregate employment, service jobs have become increasingly concentrated in aggregate clusters. This is reflected by the signs of the coefficients on initial total employment: negative for non-service sectors, and positive for all service sectors ('transportation and utilities', 'wholesale', 'retail', 'FIRE', and 'other services'), though the coefficient on 'FIRE' is not significant.

Taking these two results together, if it had not been for services, counties would have become increasingly alike both in employment size and structure. However, services have been pushing the other way by concentrating in high employment areas. Add to that the increasing weight of services in the economy, and it is not surprising to find that aggregate employment has actually been concentrating: the coefficient on total employment in the first column of Table 2 is positive. In other words, metropolitan counties and cities have been thriving because of services. The vanishing importance of distance and geography, as suggested by developments in the manufacturing sector, has been more than offset by the behavior of services.

Compared to standard results in the urban literature, some of our findings are novel. Two differences are worth mentioning. First, while Chatterjee and Carlino (2001) document increased deconcentration across urban areas between 1951 and 1994, we find the opposite is true across counties: our regressions show aggregate employment becoming more concentrated. Second, our results also differ at the sectoral level. Most studies on metropolitan areas suggest suburbanization has been happening across the board, including in the service sectors (Macauley, 1985). Instead, using county data, we find that only non-service sectors are leaving areas of high aggregate employment.

As noted in the introduction, there are several possible interpretations consistent 
with the different behavior of service and non-service sectors. We will briefly discuss four such explanations: the drop in transport costs; the overall growth in employment; environmental regulation; and technological change. Lower transport costs may have weakened agglomeration economies in manufacturing, allowing firms to locate in less congested areas, further away from consumers. That same drop in transport costs may have given an opportunity to services, traditionally considered non-tradeables, to start benefitting from clustering. As for the overall growth in employment, Chatterjee and Carlino (2001) have argued that this has caused congestion costs to rise faster in more dense urban areas. In a multi-sector setting, this could possibly explain why large agglomerations have seen less land-intensive service jobs replacing more land-intensive manufacturing activity. Another candidate for explaining the different behavior of services is environmental regulation. Tougher restrictions in urban areas have pushed manufacturing to less dense areas with laxer regulation; instead, services have moved in. Finally, technological change may also have played a role. Carlino (1985), for instance, remarks that manufacturing has become more land-intensive (increasing the cost of congestion) and more automated (decreasing the necessity to be close to a pool of skilled workers). Both effects point to manufacturing moving away from large agglomerations. Kolko (1999) makes the reverse argument for services, claiming an increased need to be close to qualified urban workers. Distinguishing between which of these different hypothesis is driving our results is left for future research; our paper is limited to describing a number of new stylized facts about the spatial distribution of employment across U.S. counties.

Although our regressions seem to imply that sectoral clusters are losing importance - given the negative coefficients on initial sectoral employment shares - the raw data do not always corroborate that view. Table 3 reports the logs of the standard deviations of sectoral employment in 1972 and 2000. It turns out that most of the service sectors ('retail', 'FIRE' and 'other services') have become more concentrated, suggesting service clusters have become more prominent. The answer to this apparent contradiction lies in the positive coefficients on initial aggregate employment for the service sectors in Table 2. Though services have been moving away from sector-specific clusters, they 
have become increasingly concentrated in areas of high aggregate employment, such as cities. If, as is the case, services already started off being over-represented in metropolitan areas, then these results are consistent with service employment having become overall more concentrated.

\section{[Insert Table 3 here]}

The coefficients on initial employment are easy to interpret. Take, for instance, the coefficient of 0.0015 on initial total employment for 'retail'. This means that a $1 \%$ increase in aggregate employment would have led to an annual increase in 'retail' job growth of $0.0015 \%$. Maybe more tellingly, if county $A$ started out with aggregate employment of 1 million and county $B$ with aggregate employment of 100,000, 'retail' employment growth between 1972 and 2000 would have been $9.7 \%$ higher in $A$ than in $B$.

As mentioned before, we think of changes in the spatial distribution as movements from one steady state to another. Given the high degree of capital and labor mobility across U.S. counties, we feel this view makes sense. However, the same distributional changes can also be interpreted in a transitional dynamics framework (Barro and Salai-Martin, 1995). This alternative interpretation is hard to reconcile with some of our regression results though. Take, for instance, the positive coefficient on initial employment in the regression for total employment (the first column in Table 2). According to the Barro-Sala-i-Martin convergence view, this means that eventually all economic activity would concentrate in Los Angeles county, ${ }^{12}$ a hardly credible prediction. In contrast, our framework does not pose any interpretational problems. A positive coefficient simply means that employment became more concentrated. Since we regard these developments as driven by exogenous changes in economic conditions between 1972 and 2000, there is no presumption that these trends will persist. From historical evidence on spatial concentration we know that extrapolating trends into the future makes little sense. Manufacturing, for instance, was highly decentralized prior to the industrial revolution, at which point it started to concentrate in cities. We are now witnessing the opposite: manufacturing is

\footnotetext{
${ }^{12}$ Los Angeles is the county with the highest total employment in 1972.
} 
spreading out again.

The control variables in Table 2 give further details about changes in the economy's spatial distribution. The positive coefficients on 'county area' for most sectors say that larger counties experienced faster employment growth. This indicates local crowding out through, for instance, land prices. This negative relation between employment density and employment growth has been previously pointed out by Carlino and Chatterjee (2002) for the case of urban areas. Surprisingly maybe, the only two sectors with negative coefficients on 'county area' are 'manufacturing' and 'wholesale', two relatively land intensive sectors. The negative coefficients on 'latitude' for most sectors indicate jobs having moved South, a well documented finding (Blanchard and Katz, 1992; Glaeser, Scheinkman and Shleifer, 1995; Hanson, 1998). The evidence on 'longitude' is not as clear: whereas the overall economy has been moving West, as reflected by the positive coefficient on 'longitude', the effect is not always statistically significant. Moreover, some of the service sectors, such as 'retail' and 'other services', have been moving East. These results obtain after we control for being located on one of the coasts. The longitude and latitude effects are largely mitigated for counties located in states on the Eastern and Western seaboards, though this positive effect does not seem to be stronger along the coasts. Once we control for being in a state bordering the ocean, there is no additional positive effect for counties being located on the coasts. We find no evidence of the Gulf of Mexico and the Mexican border having affected the spatial distribution of activity within the U.S. (although it might have affected it in Mexico). Maybe surprisingly, the Canadian border had a negative effect on growth across nearly all sectors.

\subsection{Including spatial spillovers}

The next set of regressions includes the effect of neighboring counties. Model $\mathbf{2}$ is our most complete - and preferred — specification. We use the roughness penalty approach to determine point estimates; standard errors are calculated by applying the Conley correction for spatial autocorrelation. ${ }^{13}$ As in Model 1, we again distinguish

\footnotetext{
${ }^{13}$ As we pointed out in the first section, bootstrapping the Conley standard errors is not feasible. Without the Conley correction, bootstrapped and OLS standard errors are virtually identical. This suggests
} 
between localization and urbanization economies, with the difference that we now take into account spatial spillovers. The effects of geographical features largely confirm the results of Model 1, so we refrain from reporting them here.

Including spatial spillovers allows us to complete our description of location dynamics. Take, for instance, services. If declining transport costs paved the way for spatial concentration, we would expect service centers to have emerged by absorbing jobs from the surrounding hinterland. At least this is what central place theory would tell us (Christaller, 1933). By explicitly taking into account spatial effects, our regressions are able to check the consistency of that prediction. Likewise, if agglomeration economies in manufacturing have been weakening, we would expect manufacturing jobs to have moved out of clusters to nearby less congested areas. Again, our empirical analysis can verify this prediction.

Given the contrast between service and non-service sectors uncovered in Model 1, we start by presenting pooled regressions for both of these groups. ${ }^{14}$ The graphs in Figure 1 show how aggregate employment at different distances has affected sectoral employment growth. The results are largely consistent with what we expect. The pattern for the non-service sectors — such as manufacturing and construction — shows employment having moved away from centers of high aggregate employment to nearby locations. The coefficients are negative for distances below 20 kilometers, and are then slightly positive for distances between 20 and 70 kilometers. In other words, the presence of high aggregate employment in a radius of 15 kilometers had a negative effect on non-service job growth, whereas the presence of high aggregate employment 20 to 70 kilometers away had a positive, though small, effect on non-service growth. Put differently, aggregate employment clusters (and nearby areas) have experienced a relative decline in non-service employment, whereas areas slightly farther out have grown relatively faster.

that the bias introduced by not bootstrapping the Conley standard errors (to account for roughness penalty correction) is negligible.

${ }^{14}$ In these regressions the service sectors are 'transportation and utilities', 'wholesale', 'retail', 'FIRE', and 'other services'; and the non-service sectors are 'farming', 'agricultural services', 'mining', 'construction', and 'manufacturing'. The government sectors have been left out of these regressions. 
[Insert Figure 1 here]

In contrast, but in line with our findings in Model 1, service sectors exhibit a different pattern: they grew faster in aggregate clusters and slower in nearby areas. As can be seen in Figure 1, the coefficients are positive at distances below 5 kilometers, and slightly negative at distances between 5 and 20 kilometers. This implies that services grew faster in areas of high aggregate employment, and slower in nearby areas. One interpretation is that service jobs have been concentrating in places of high economic activity by attracting jobs from the surrounding areas.

As for localization externalities, Figure 2 shows the effect of sectoral employment shares at different distances on sectoral employment growth. Results look similar for non-service and service sectors, with negative coefficients at short distances and slightly positive coefficients at intermediate distances. After controlling for the effect of aggregate employment, this points to sectoral employment clusters having become more spread out.

\section{[Insert Figure 2 here]}

The pooled regressions give an idea of how service and non-service sectors behaved 'on average'. To get a more detailed view, we now disaggregate and look at the 13 different sectors in our data set. Figure 3 analyzes the spatial effects of changing urbanization economies on sectoral employment growth. In line with the pooled regressions, for the non-service sectors the coefficients are always negative for distances below 15-20 kilometers. However, the positive effect at further distances depends on the sectors. For instance, in 'construction' and 'manufacturing', employment growth is clearly higher in counties 30 to 70 kilometers away from large agglomerations. This is the story of the suburbanization of manufacturing: industry has moved out of densely populated metropolitan counties to less congested places not too far away. In other sectors, such as 'farming', this positive effect at intermediate distances is largely absent. Farm jobs have been lost in urban areas, but there is no indication that they have stayed 'close by'. 
[Insert Figure 3 here]

The different service sectors have generally grown faster in large agglomerations, and slower in areas 5 to 20 kilometers away from those aggregate clusters. This suggests services increasingly locating in metropolitan areas by leaving the immediate hinterland. As can be seen in Table 4, the statistical significance of the negative coefficients between 5 and 20 kilometers is rather weak though. Moreover, Figure 3 reveals some interesting differences across different service sectors. For instance, in 'FIRE' and 'retail', aggregate employment has a positive effect at intermediate distances of 30 to 60 kilometers. This means that retail job growth is greater in counties 30 to 60 kilometers away from large agglomerations. It is not immediately clear how to interpret those results in the framework of our model. It may be consistent with economic geography theories which predict a hierarchy of towns and cities some distance from each other (Isard, 1956).

\section{[Insert Table 4 here]}

Figure 4 shows the spatial effect of changing localization economies for each individual sector. Across the board, sectoral job growth is lower in a radius of about 20 kilometers around sector-specific clusters. At intermediate distances, the picture is less clear. For instance, in 'construction', 'retail' and 'FIRE', job growth is higher in areas 20 to 60 kilometers away from sectoral clusters. However, in sectors such as 'farming' and 'other services' there does not seem to be any effect at intermediate distances. To see this more clearly, Table 5 summarizes the statistical significance of employment shares at different distances.

[Insert Figure 4 here]

[Insert Table 5 here]

Our model simultaneously estimates the effect of changes in localization economies, 
changes in urbanization economies, and geographical features. It would be interesting to get a feel for the relative explanatory power of these different groups of variables. We address this question in two different ways. First, in Table 6 we report the variance decomposition. One obvious problem is that the variance shares do not add up to 1 , because the covariances between the different groups of variables also matter. The interpretation of this decomposition is therefore not straightforward. However, the results suggest that for non-service sectors localization economies matter a lot more than urbanization economies when it comes to understanding what drives sectoral employment growth. The picture for services is less clear: in 'retail', 'FIRE', and 'other services' the relative importance of localization and urbanization economies is quite balanced. However, for 'transportation and utilities' and 'wholesale', localization economies continue to dominate. Second, for each sector we run three separate growth regressions: one including localization variables, another including urbanization economies, and a third with geographical features. Table 7 reports the $R^{2}$ 's for these regressions. This methodology has its own problems, since each of these growth regressions suffers from an omitted variables bias. However, the overall picture that emerges is in line with what we found in Table 6. In non-service sectors localization economies are clearly more important than urbanization economies, whereas for service sectors the picture is mixed: in 'retail' and 'other services' both forces are balanced, in 'FIRE' urbanization economies dominate, and in 'transportation and utilities' and 'wholesale' localization economies take the upper hand.

[Insert Table 6 here]

[Insert Table 7 here]

\section{Conclusion}

In this paper we studied how the spatial distribution of employment across U.S. counties has changed between 1972 and 2000. We found that aggregate employment has become geographically more concentrated. This outcome seems to be driven by part of the service 
sectors. Whereas non-service employment, such as manufacturing, has been spreading out, most service jobs have become increasingly clustered in areas of high aggregate employment. When analyzing these dynamics, we distinguished between urbanization and localization economies. We also explicitly took into account the spatial dimension by regressing employment growth on initial employment at different distances. In contrast to the existing literature, we estimated these spatial effects in a non-parametric way.

This paper obviously leaves a number of questions unanswered. In particular, two issues stand out. First, our analysis is limited to describing a number of stylized facts about employment in U.S. counties; we did not venture into trying to explain what is driving the spatial dynamics. If one is interested in policy-making, this is a clear limitation. Second, the fact that county employment is becoming more concentrated, whereas urban employment is becoming less concentrated, suggests the existence of nonlinearities in the relation between initial employment and employment growth. This issue requires further exploration.

\section{References}

[1] Barro, R.J. and Sala i Martin, X., 1992. Convergence, Journal of Political Economy, $100,223-251$.

[2] Beeson, P.E., DeJong, D.N., and Troesken, W., 2001. Population Growth in U.S. Counties, 1840-1990, Regional Science and Urban Economics, 31, 669-699.

[3] Blanchard, O. and Katz, L., 1992. Regional Evolutions, Brookings Papers on Economic Activity, 0, 1-61.

[4] Carlino, G.A., 1985. Declining City Productivity and the Growth of Rural Regions: A Test of Alternative Explanations, Journal of Urban Economics, 18, 11-27.

[5] Carlino, G. and Chatterjee, S., 2001. Aggregate Metropolitan Employment Growth and the Deconcentration of Metropolitan Employment, Journal of Monetary Economics, 48, 549-583.

[6] Carlino, G. and Chatterjee, S., 2002. Employment Deconcentration: A New Perspective on America's Postwar Urban Revolution, Journal of Regional Science, 42, 455-475.

[7] Christaller, W., 1933. Die zentralen Orte in Süddeutschland. Jena: G. Fischer. 
[8] Ciccone, A. and Hall, R.E., 1996. Productivity and the Density of Economic Activity, American Economic Review, 86, 54-70.

[9] Combes, P.P., 2000. Economic Structure and Local Growth: France, 1984-1993, Journal of Urban Economics, 47, 329-355.

[10] Conley, T.G., 1999. GMM Estimation with Cross Sectional Dependence, Journal of Econometrics, 92, 1-45.

[11] Dumais, G., Ellison, G. and Glaeser, E., 2002. Geographic Concentration as a Dynamic Process, Review of Economics and Statistics, 84, 2, 193-204.

[12] Ellison, G. and Glaeser, E., 1997. Geographic Concentration in U.S. Manufacturing Industries: A Dartboard Approach, Journal of Political Economy, 105, 889-927.

[13] Fafchamps, M., 1997. Mobile Capital, Local Externalities, and Industrialization, Journal of Comparative Economics, 25, 345-65.

[14] Fujita, M, Krugman, P. and Venables, A.J., 1999. The Spatial Economy: Cities, Regions, and International Trade, Cambridge, Mass.: MIT Press.

[15] Fujita, M. and Ogawa, H., 1982. Multiple Equilibria and Structural Transition of Non-Monocentric Urban Configurations, Regional Science and Urban Economics, $12,161-196$.

[16] Glaeser, E.L., 1998. Are Cities Dying?, Journal of Economic Perspectives, 12(2), 139-160.

[17] Glaeser, E.L., and Kahn, M.E., 2001. Decentralized Employment and the Transformation of the American City, NBER Working Paper $\sharp 8117$.

[18] Glaeser, E. L., Kallal, H., Scheinkman, J., and Shleifer, A., 1992. Growth in Cities, Journal of Political Economy, 100, 1126-1152.

[19] Glaeser, E.L., Scheinkman, J. and Shleifer, A., 1995. Economic Growth in a CrossSection of Cities, Journal of Monetary Economics, 36, 117-143.

[20] Glaeser, E.L., and Shapiro, J., 2001. Is There A New Urbanism? The Growth of U.S. Cities in the 1990s, Harvard Institute of Economic Research, Discussion Paper Number 1925.

[21] Good I. and Gaskins R., 1971. Nonparametric Roughness Penalties for Probability Densities, Biometrika, 58, 255-277.

[22] Hanson, G.H., 1998. Market Potential, Increasing Returns and Geographic Concentration, NBER Working Paper $\sharp 6429$.

[23] Harris, C., 1954. The Market as a Factor in the Localization of Industry in the United States, Annals of the Association of American Geographers, 64, 315-348. 
[24] Henderson, J.V., 1974. The Sizes and Types of Cities, American Economic Review, $64,640-656$.

[25] Henderson, J.V, Kuncoro, A., and Turner, M., 1995. Industrial Development in Cities. Journal of Political Economy, 103, 1067-1085.

[26] Isard, W., 1956. Location and Space Economy, Cambridge, Mass.: MIT Press.

[27] Jaffe, A.B., Trajtenberg, M. and Henderson, R., 1993. Geographic Localization of Knowledge Spillovers as Evidenced by Patent Citations, Quarterly Journal of Economics, 108, 577-98.

[28] Kim, S., 1995. Expansion of Markets and the Geographic Distribution of Economic Activities: The Trends in U.S. Regional Manufacturing Structure, 1860-1987, Quarterly Journal of Economics, 110, 881-908.

[29] Kolko, J., 1999. Can I Get Some Service Here?, mimeo, Harvard University.

[30] Macauley, M.K., 1985. Estimation and Recent Behavior of Urban Population and Employment Density Gradients, Journal of Urban Economics, 18, 251-260.

[31] Mankiw, N.G., Romer, D. and Weil, D.N., 1992. A Contribution to the Empirics of Economic Growth, Quarterly Journal of Economics, 107, 407-437.

[32] Marshall, A., 1890. Principles of Economics, London: McMillan, reprinted 1920.

[33] Mills, E., 1967. An Aggregative Model of Resource Allocation in a Metropolitan Area, American Economic Review, 57, 197-210.

[34] Mills, E.S., and Hamilton, B.W., 1994. Urban Economics, 5th edition, Harper Collins College Publishers.

[35] Rappaport, J. and Sachs, J., 2003. The United States as a Coastal Nation, Journal of Economic Growth, 8, 5-46.

[36] Rodríguez Clare, 1996. The Division of Labor and Economic Development, Journal of Development Economics, 49, 3-32.

[37] Silverman B., 1982. On the Estimation of a Probability Density Function by the Maximum Penalized Likelihood Method, Annals of Statistics, 10, 795-810.

[38] Silverman B., 1984. Spline Smoothing: The Equivalent Variable Kernel Method, Annals of Statistics, 12, 898-916.

[39] Wallsten, S.J., 2001. An Empirical Test of Geographic Knowledge Spillovers Using Geographic Information Systems and Firm-Level Data, Regional Science and Urban Economics, 31, 571-599. 

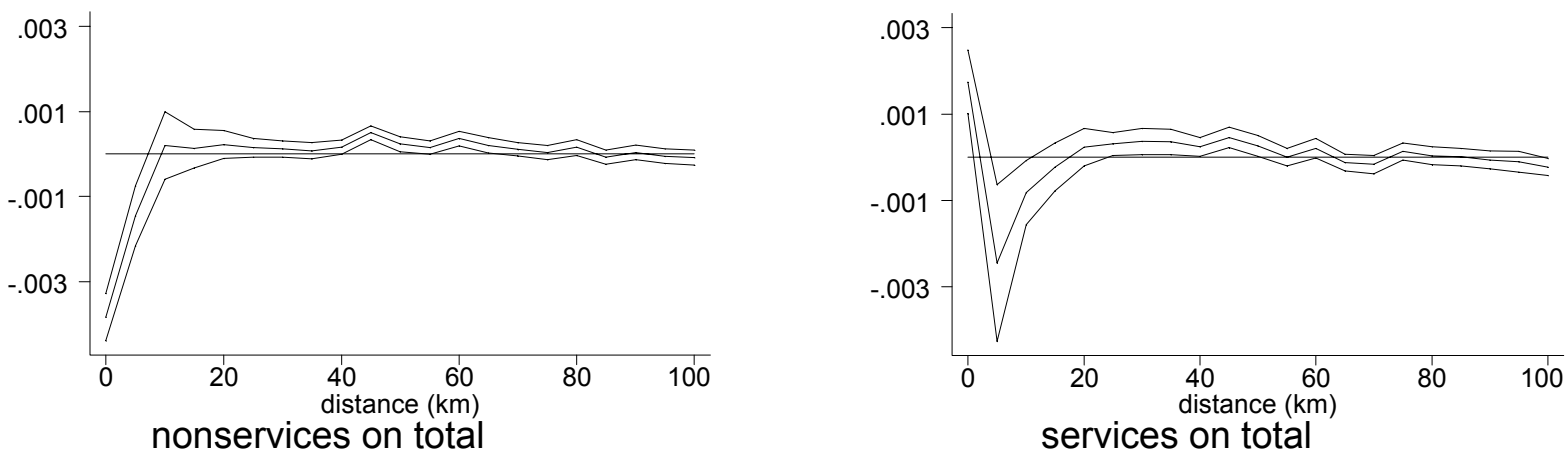

Figure 1: Pooled regressions for non-service and service sectors.

Effect of aggregate employment (logs) on sectoral employment growth with $90 \%$ confidence interval. 

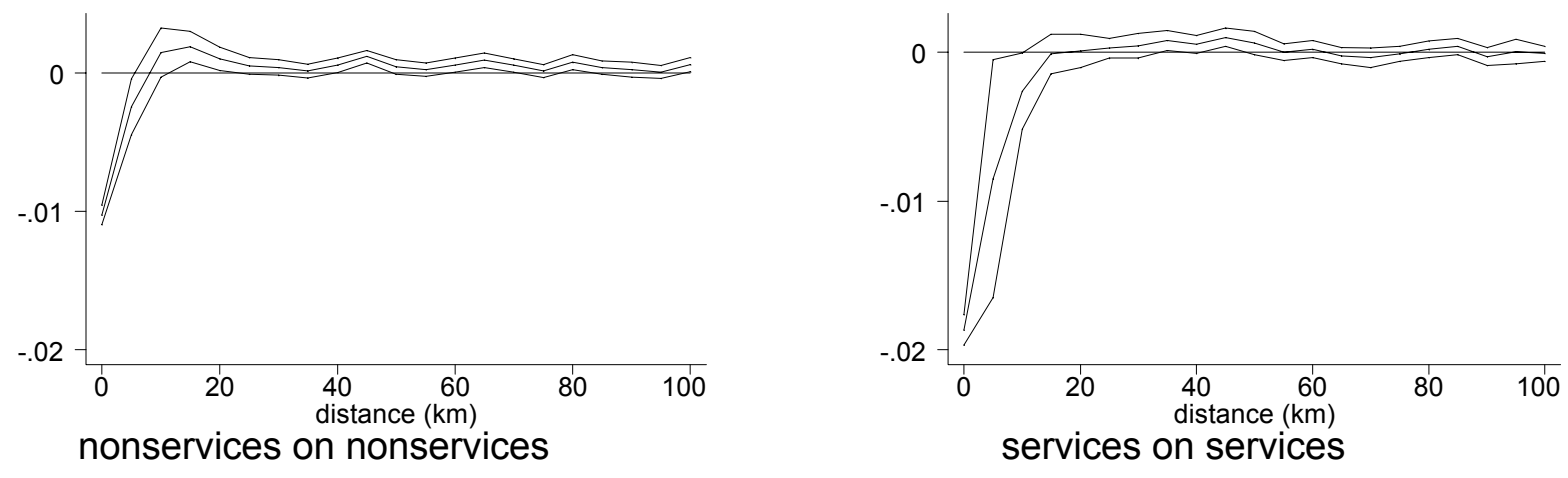

Figure 2: Pooled regressions for non-service and service sectors.

Effect of sectoral employment (logs) on sectoral

employment growth with $90 \%$ confidence interval. 

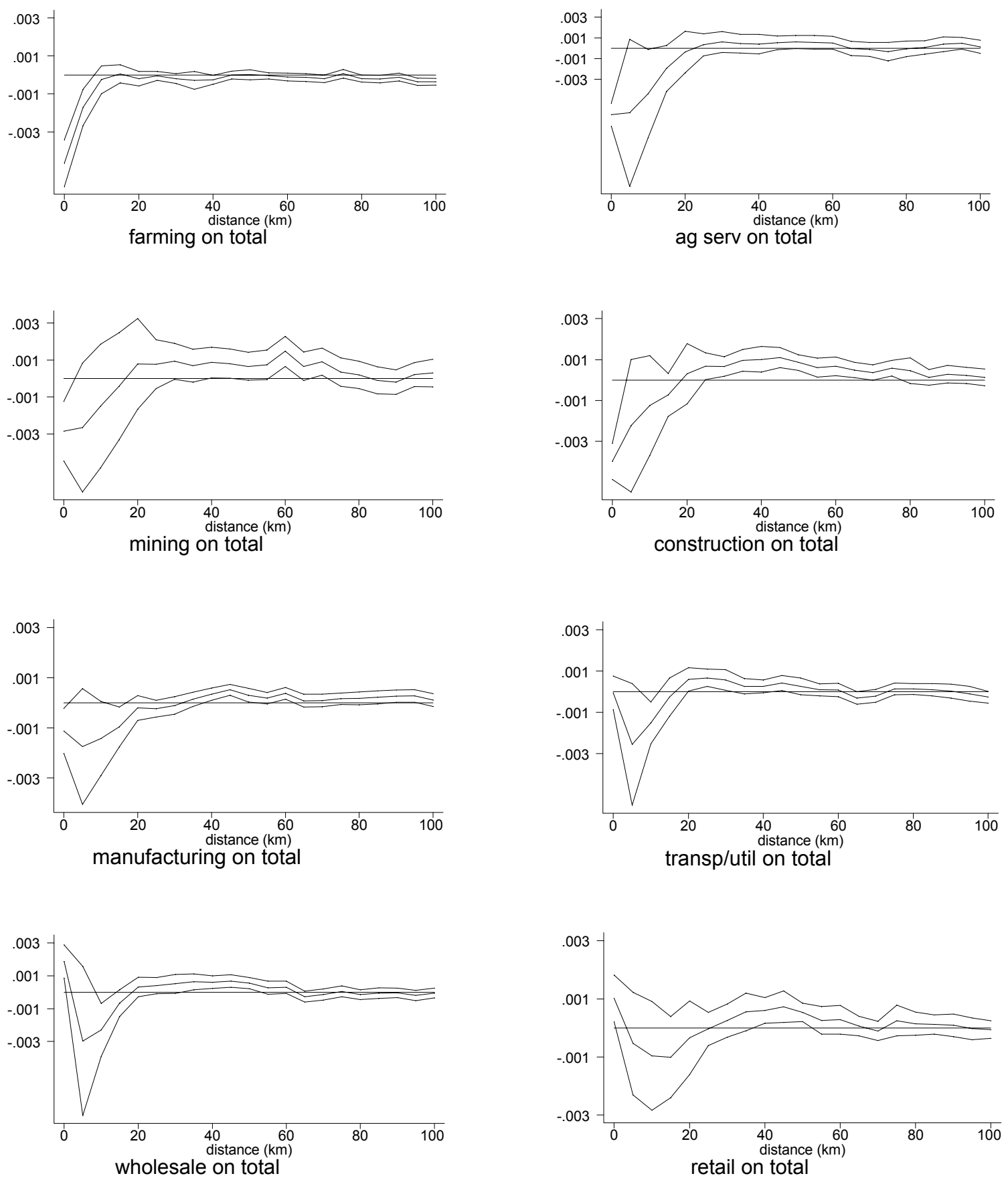

Figure 3: Effect of aggregate employment (logs) on sectoral employment growth with $90 \%$ confidence interval 

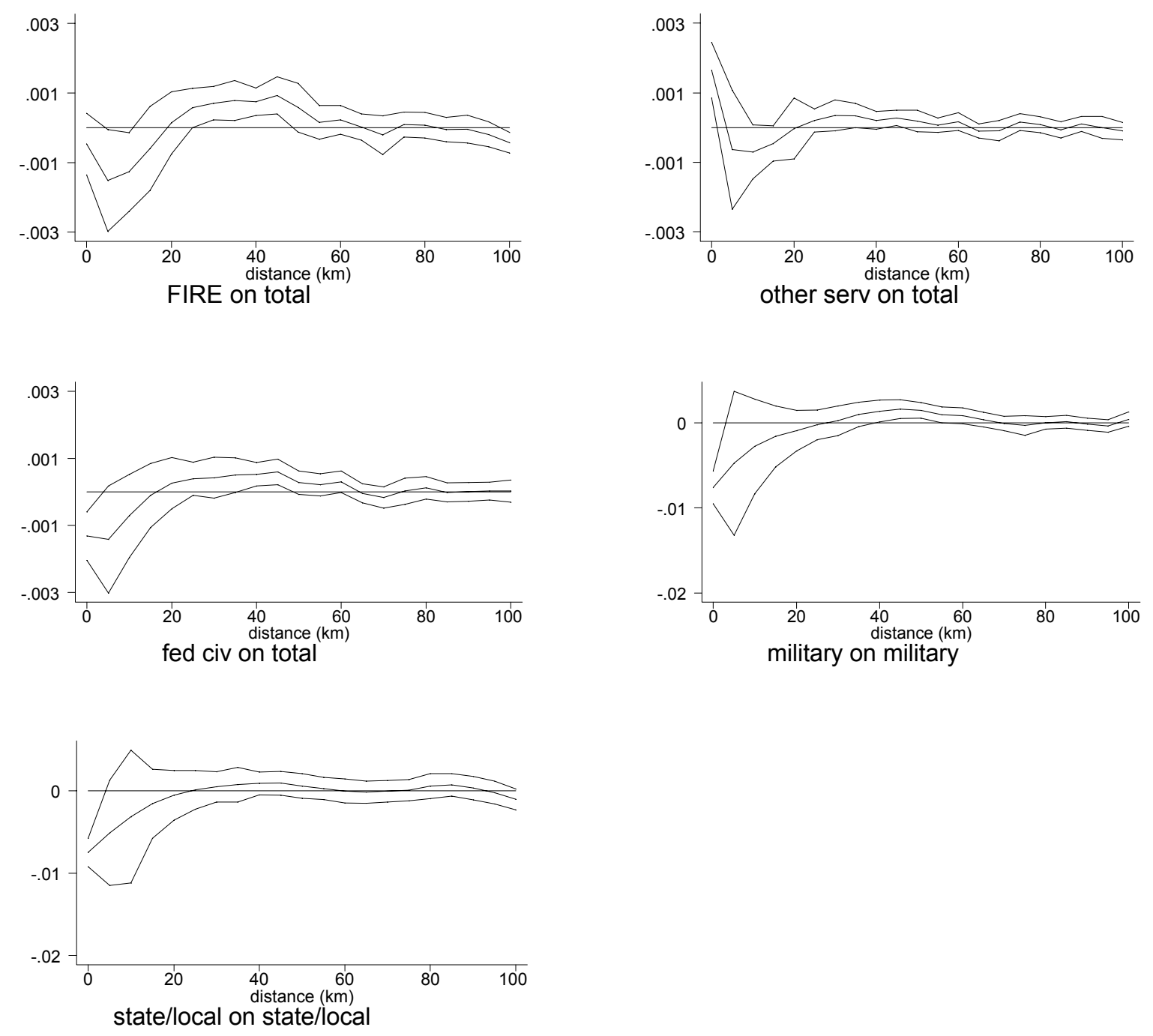

Figure 3: Effect of aggregate employment (logs) on sectoral employment growth with $90 \%$ confidence interval 


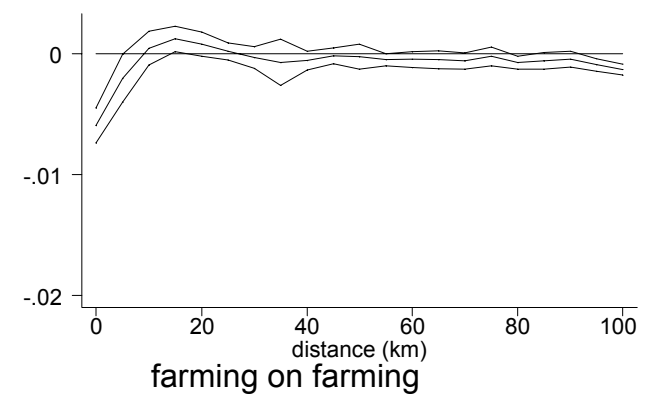

farming on farming
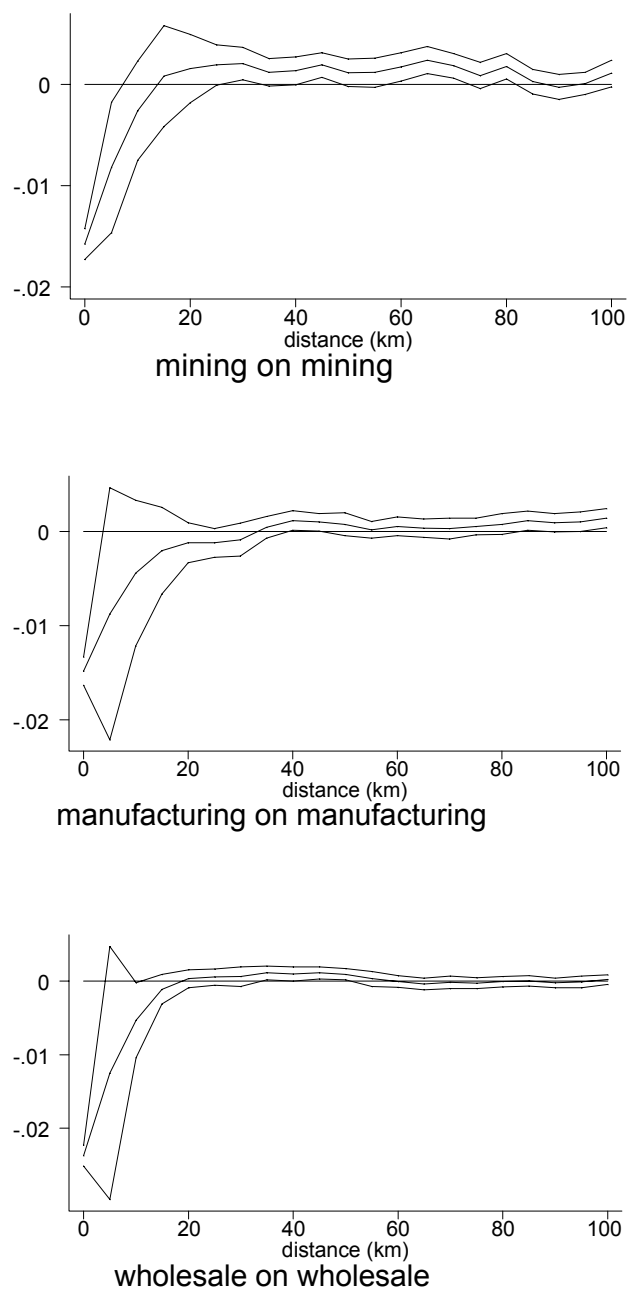

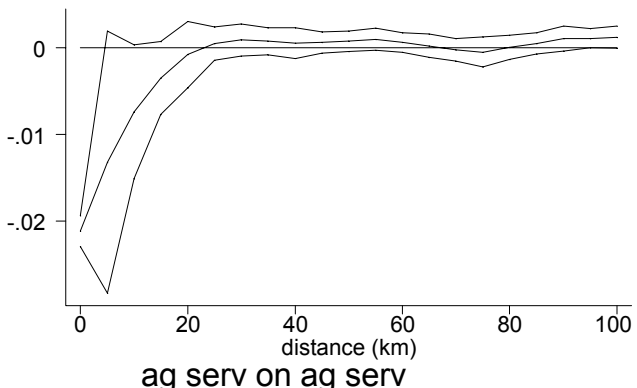

ag serv on ag serv
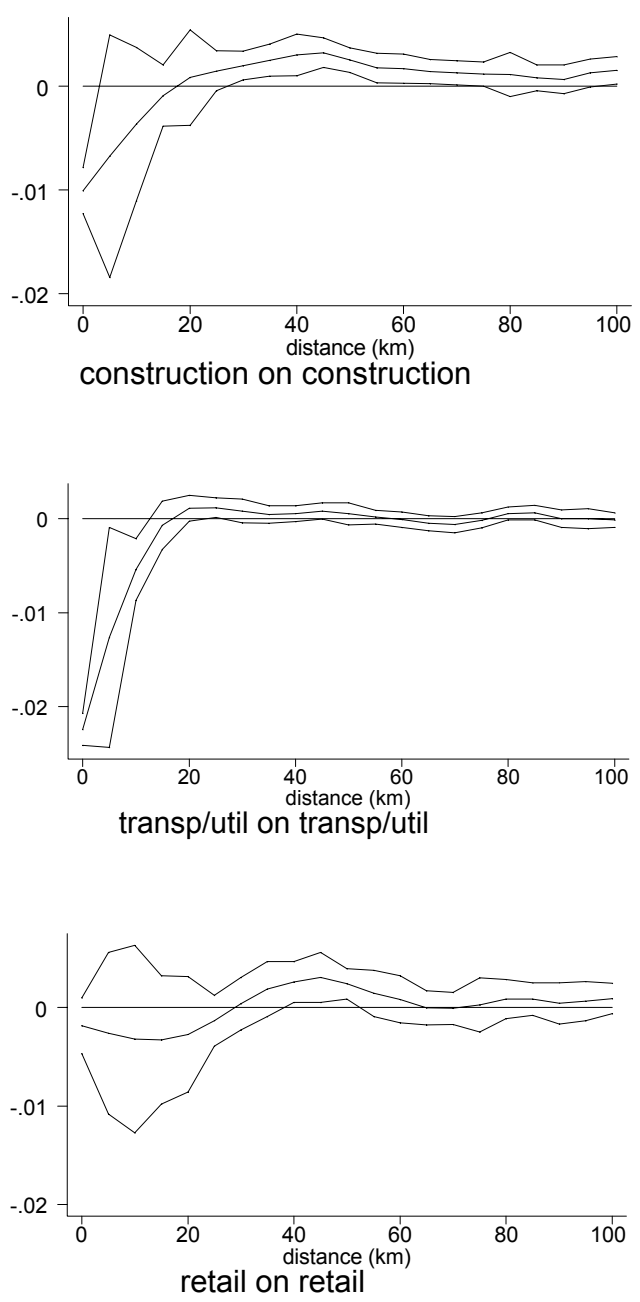

Figure 4: Effect of sectoral employment share (logs) on sectoral employment growth with $90 \%$ confidence interval 

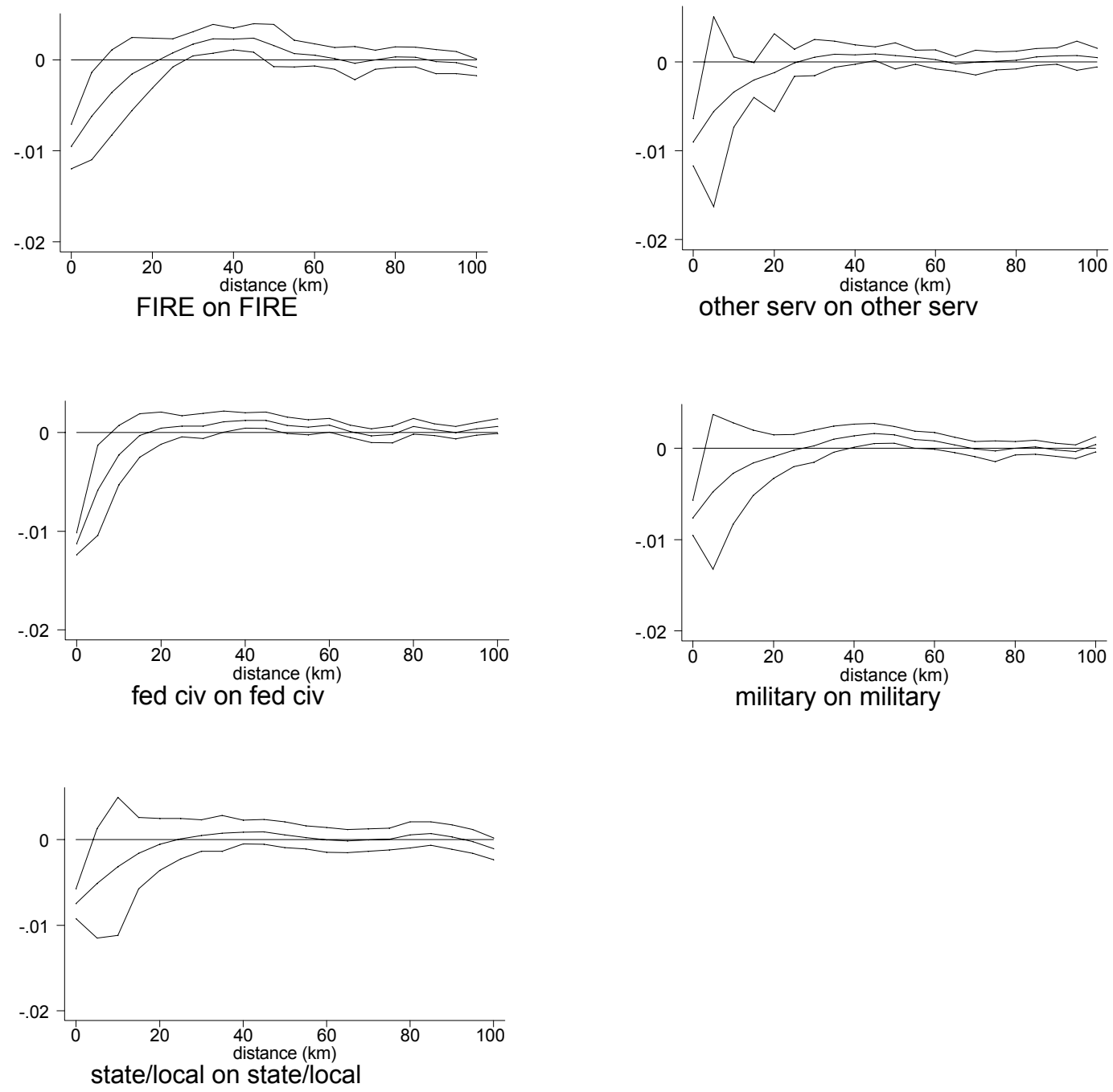

Figure 4: Effect of sectoral employment share (logs) on sectoral employment growth with $90 \%$ confidence interval 
Table 1: Average county sectoral employment in 1972 and 2000 (Summary statistics)

\begin{tabular}{|l||c|c|c|}
\hline Sector & Employment 1972 & Employment 2000 & Growth rate \\
\hline Total & 30487 & 54026 & $77 \%$ \\
Farming & 1254 & 1006 & $-20 \%$ \\
Agricultural services & 194 & 1025 & $428 \%$ \\
Mining & 272 & 422 & $55 \%$ \\
Construction & 1549 & 3350 & $116 \%$ \\
Manufacturing & 6453 & 6746 & $5 \%$ \\
Transportation/Utilities & 1666 & 2871 & $72 \%$ \\
Wholesale & 1486 & 2718 & $83 \%$ \\
Retail & 4664 & 8889 & $91 \%$ \\
FIRE & 2198 & 4560 & $107 \%$ \\
Other services & 6048 & 17564 & $190 \%$ \\
Federal civilian & 920 & 933 & $1 \%$ \\
Military & 898 & 659 & $-27 \%$ \\
State/Local & 3469 & 5736 & $65 \%$ \\
\hline
\end{tabular}

Source: REIS, Bureau of Economic Analysis 
Table 2: Sectoral employment growth on sectoral employment share, total employment, and control variables

\begin{tabular}{|c|c|c|c|c|c|c|c|}
\hline & Total & Farming & Ag serv & Mining & Constr & Manuf & Trans/util \\
\hline constant & 0.0084 & 0.0220 & -0.0325 & -0.0742 & 0.0452 & 0.0018 & -0.0646 \\
\hline 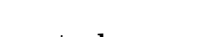 & $(0.99)$ & $(2.34)$ & $(2.31)$ & $(2.84)$ & $(3.49)$ & $(0.14)$ & $(5.31)$ \\
\hline sect share & & $\begin{array}{c}-0.0065 \\
(8.19)\end{array}$ & $\begin{array}{r}-0.0207 \\
(18.87)\end{array}$ & $\begin{array}{r}-0.0097 \\
(1249)\end{array}$ & -0.0078 & -0.0128 & -0.0240 \\
\hline total empl & 0.0009 & -0.0052 & -0.0056 & -0.0006 & -0.0028 & -0.0008 & 0.0010 \\
\hline & $(2.47)$ & $(7.07)$ & $(8.10)$ & $(0.63)$ & $(5.44)$ & $(1.45)$ & $(2.15)$ \\
\hline area & $7.92 \mathrm{E}-07$ & $9.86 \mathrm{E}-07$ & 7. $60 \mathrm{E}-07$ & 1.70E-06 & $8.71 \mathrm{E}-07$ & $-6.84 \mathrm{E}-07$ & $4.61 \mathrm{E}-07$ \\
\hline & (2.94) & (3.48) & (2.13) & (1.96) & (2.24) & (1.35) & (1.28) \\
\hline latitude & $\begin{array}{c}-0.0206 \\
(3.27)\end{array}$ & $\begin{array}{c}-0.0108 \\
(1.72)\end{array}$ & $\begin{array}{c}-0.0099 \\
(1.10)\end{array}$ & $\begin{array}{c}-0.0820 \\
(4.48)\end{array}$ & $\begin{array}{c}-0.0288 \\
(3.38)\end{array}$ & $\begin{array}{c}-0.0011 \\
(0.13)\end{array}$ & $\begin{array}{c}-0.0239 \\
(3.12)\end{array}$ \\
\hline longitude & 0.0071 & 0.0059 & 0.0220 & 0.0547 & -0.0001 & -0.0052 & 0.0063 \\
\hline - & $(1.78)$ & $(1.73)$ & $(3.74)$ & $(4.74)$ & $(0.02)$ & $(0.84)$ & $(1.40)$ \\
\hline east coast & 0.0029 & -0.0102 & 0.0074 & 0.0139 & 0.0013 & -0.0092 & 0.0046 \\
\hline & (1.06) & (2.79) & $(2.20)$ & (1.99) & $(0.45)$ & $(2.83)$ & $(1.36)$ \\
\hline lakes & 0.0031 & -0.0029 & -0.0007 & $\begin{array}{l}0.0163 \\
(204)\end{array}$ & 0.0052 & -0.0002 & -0.0004 \\
\hline west coast & 0.0023 & 0.0020 & -0.0004 & -0.0103 & 0.0066 & -0.0012 & -0.0015 \\
\hline & $(0.81)$ & $(0.57)$ & $(0.12)$ & $(1.35)$ & (1.97) & $(0.31)$ & $(0.43)$ \\
\hline gulf & 0.0052 & 0.0021 & 0.0055 & 0.0028 & 0.0033 & -0.0024 & 0.0054 \\
\hline 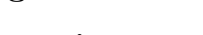 & $(1.14)$ & $(0.28)$ & (1.15) & $(0.38)$ & $(0.64)$ & $(0.46)$ & $(0.92)$ \\
\hline mexico & 0.0000 & -0.0055 & 0.0066 & 0.0007 & -0.0094 & -0.0038 & 0.0067 \\
\hline 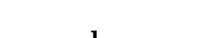 & $(0.00)$ & $(2.81)$ & (1.13) & $(0.05)$ & $(1.52)$ & $(0.69)$ & (1.64) \\
\hline canada & -0.0051 & 0.0017 & -0.0034 & 0.0051 & -0.0105 & -0.0058 & -0.0036 \\
\hline east state & $\begin{array}{l}(2.36) \\
0.0055\end{array}$ & $\begin{array}{c}(0.58) \\
-0.0040\end{array}$ & $\begin{array}{l}(0.98) \\
0.0078\end{array}$ & $\begin{array}{l}(0.58) \\
0.0030\end{array}$ & $(2.12)$ & $\begin{array}{c}(1.41) \\
-0.0031\end{array}$ & 0 \\
\hline & $(3.11)$ & $(2.21)$ & $(3.03)$ & $(0.79)$ & $(3.14)$ & $(1.51)$ & $(0.78)$ \\
\hline west state & 0.0061 & 0.0117 & 0.0118 & -0.0181 & 0.0143 & 0.0071 & 0.0017 \\
\hline & $(2.38)$ & $(4.93)$ & $(3.14)$ & $(2.34)$ & $(3.98)$ & $(1.91)$ & $(0.57)$ \\
\hline number obs & 3072 & 3072 & 1513 & 1449 & 2752 & 2780 & 2710 \\
\hline & Wholesale & Retail & FIRE & Other serv & Fed civ & Milit & State/Loc \\
\hline constant & -0.1609 & 0.0287 & -0.0084 & -0.0198 & -0.0306 & 0.0134 & 0.0245 \\
\hline & $(12.50)$ & $(2.28)$ & $(0.64)$ & (1.83) & (3.64) & $(1.29)$ & $(3.16)$ \\
\hline sect share & -0.0264 & -0.0017 & -0.0084 & -0.0112 & -0.0112 & -0.0073 & -0.0076 \\
\hline & $(31.44)$ & $(0.96)$ & $(5.69)$ & $(6.90)$ & (15.98) & $(6.67)$ & $(7.33)$ \\
\hline total empl & 0.0038 & 0.0015 & 0.0004 & 0.0023 & -0.0008 & -0.0012 & -0.0003 \\
\hline & $(6.60)$ & $(3.12)$ & $(0.74)$ & $(5.05)$ & $(2.09)$ & $(2.56)$ & $(0.97)$ \\
\hline area & $-8.84 \mathrm{E}-07$ & $1.31 \mathrm{E}-06$ & $1.32 \mathrm{E}-06$ & $9.30 \mathrm{E}-07$ & $1.81 \mathrm{E}-06$ & $4.41 \mathrm{E}-07$ & $8.75 \mathrm{E}-07$ \\
\hline & $(1.93)$ & & & $(2.72)$ & $(5.62)$ & & \\
\hline latitude & 0.0159 & -0.0318 & -0.0323 & 0.0010 & -0.0197 & -0.0365 & -0.0584 \\
\hline 1 & $(1.96)$ & $(4.32)$ & $(4.25)$ & $(0.13)$ & $(2.96)$ & $(5.27)$ & (10.75) \\
\hline longitude & 0.0267 & -0.0056 & 0.0123 & 0.0036 & 0.0042 & -0.0107 & 0.0103 \\
\hline east coast & $\begin{array}{l}(5.66) \\
-0.0017\end{array}$ & (1.18) & $(2.42)$ & $(0.76)$ & (1.17) & (2.41) & (3.07) \\
\hline east coast & $\begin{array}{c}-0.0017 \\
(0.46)\end{array}$ & $\begin{array}{c}0.0003 \\
(0.08)\end{array}$ & $\begin{array}{c}0.0065 \\
(1.99)\end{array}$ & $\begin{array}{l}0.0048 \\
(1.51)\end{array}$ & $\begin{array}{l}0.0072 \\
(1.93)\end{array}$ & $\begin{array}{c}0.0040 \\
(1.02)\end{array}$ & $\begin{array}{l}0.0012 \\
(0.48)\end{array}$ \\
\hline lakes & -0.0082 & 0.0041 & 0.0047 & 0.0041 & 0.0038 & -0.0048 & 0.0028 \\
\hline & $(3.27)$ & $(2.08)$ & $(2.05)$ & $(2.08)$ & $(1.82)$ & $(1.90)$ & $(2.50)$ \\
\hline west coast & -0.0055 & 0.0029 & 0.0049 & 0.0056 & -0.0038 & -0.0018 & -0.0030 \\
\hline & & $(0.82)$ & $(1.59)$ & $(1.90)$ & & & $(1.02)$ \\
\hline gulf & -0.0010 & 0.0032 & 0.0041 & 0.0083 & 0.0117 & 0.0075 & 0.0009 \\
\hline & $(0.15)$ & $(0.63)$ & $(0.75)$ & $(1.56)$ & $(1.98)$ & $(1.27)$ & $(0.21)$ \\
\hline mexico & -0.0051 & -0.0021 & -0.0025 & 0.0063 & 0.0187 & 0.0019 & 0.0020 \\
\hline & $(1.10)$ & & $(0.68)$ & $(1.57)$ & & $(0.59)$ & $(0.89)$ \\
\hline canada & -0.0100 & -0.0045 & -0.0030 & -0.0038 & -0.0013 & -0.0065 & -0.0033 \\
\hline & $(3.45)$ & $(1.74)$ & (1.07) & $(1.73)$ & $(0.40)$ & $(1.54)$ & $(1.40)$ \\
\hline east state & 0.0098 & 0.0077 & 0.0083 & 0.0064 & 0.0053 & -0.0021 & 0.0076 \\
\hline & & & (3.98) & $(2.88)$ & $(3.27)$ & (1.17) & $(5.76)$ \\
\hline west state & -0.0054 & 0.0129 & 0.0027 & 0.0065 & 0.0094 & 0.0083 & 0.0077 \\
\hline & $(1.76)$ & $(4.11)$ & $(0.82)$ & $(2.04)$ & $(4.21)$ & $(2.46)$ & $(4.20)$ \\
\hline number obs & 2638 & 3050 & 2828 & 2932 & 3046 & 3028 & 3072 \\
\hline
\end{tabular}

Absolute values of t-statistics (corresponding to spatially corrected standard errors) in brackets. 
Table 3: Standard deviations of sectoral employment in 1972 and 2000 in logs

\begin{tabular}{|l|c|c|}
\hline Sector & standard deviation (logs) 1972 & standard deviation (logs) 2000 \\
\hline Total & 1.34 & 1.46 \\
Farming & 0.94 & 0.86 \\
Agricultural services & 1.33 & 1.25 \\
Mining & 1.96 & 2.25 \\
Construction & 1.51 & 1.49 \\
Manufacturing & 2.03 & 1.78 \\
Transportation/Utilities & 1.53 & 1.52 \\
Wholesale & 1.73 & 1.66 \\
Retail & 1.43 & 1.59 \\
FIRE & 1.55 & 1.61 \\
Other services & 1.49 & 1.63 \\
Federal Civilian & 1.56 & 1.55 \\
Military & 1.48 & 1.49 \\
State/Local & 1.31 & 1.37 \\
\hline
\end{tabular}

Source: REIS, Bureau of Economic Analysis 
Table 4: Statistical significance of total employment at different distances

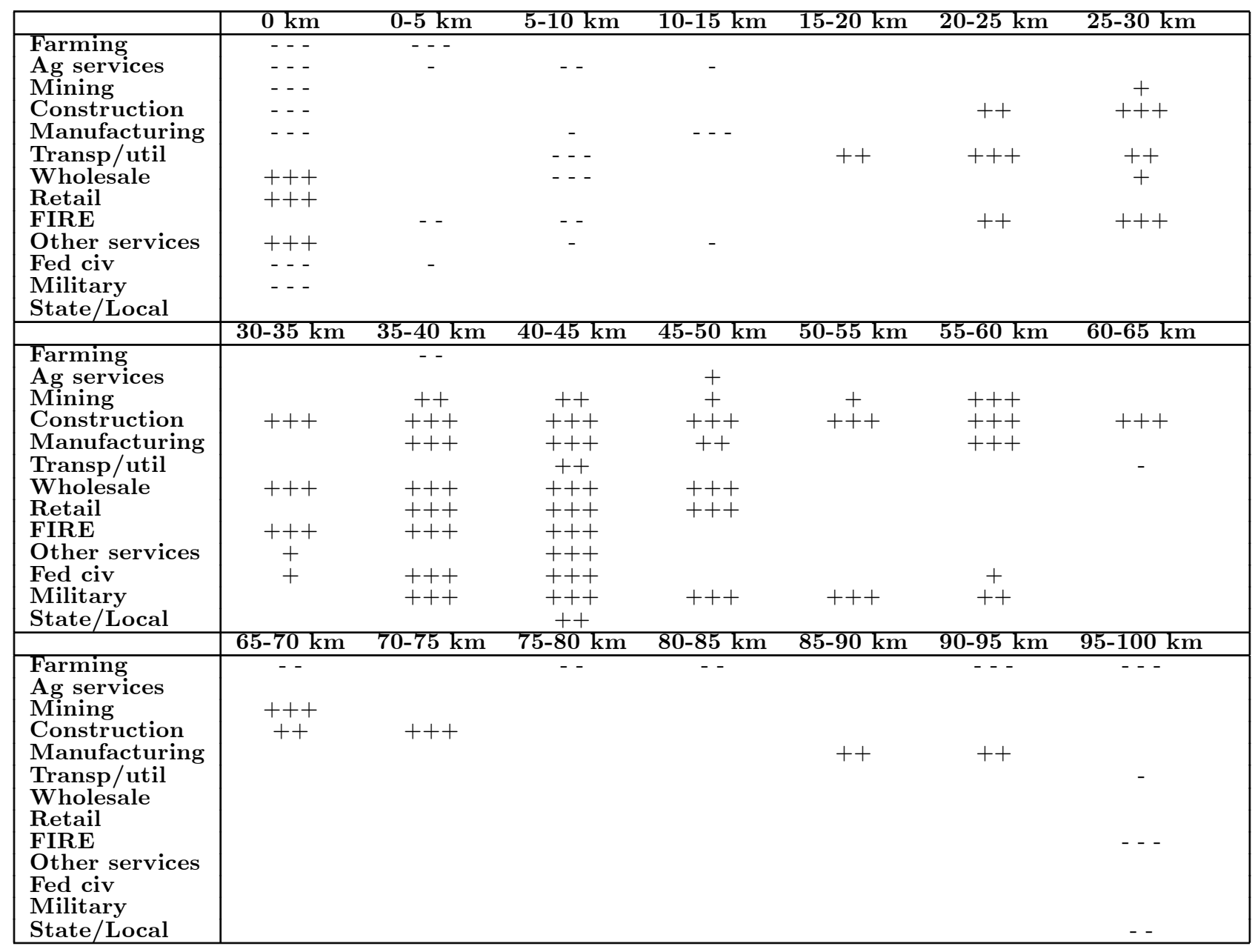
$+++(--)$ positive (negative) and significant at $5 \% ;++(--)$ at $10 \% ;+(-)$ at $15 \%$. 
Table 5: Statistical significance of employment shares at different distances

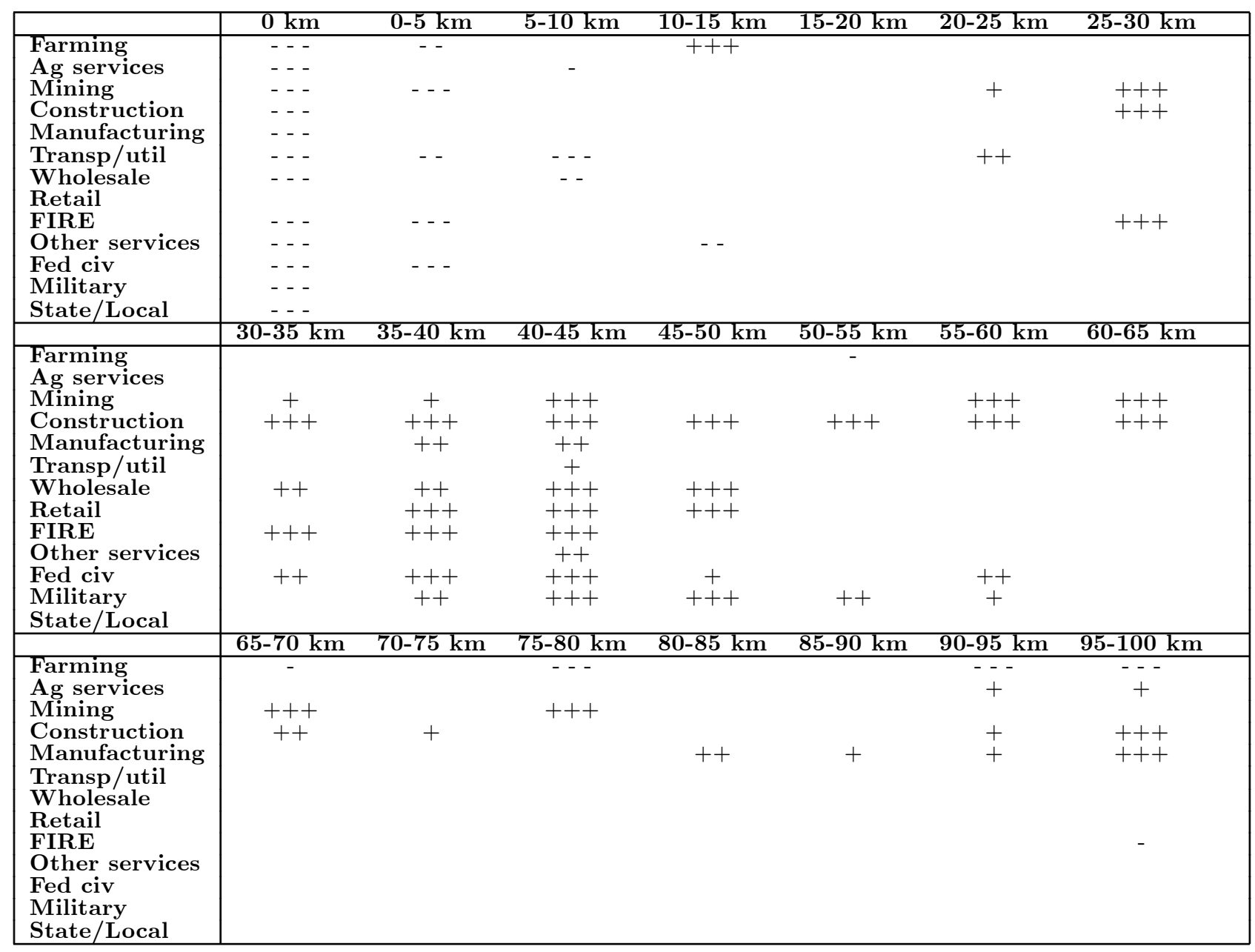
$+++\left(--_{-}\right)$positive (negative) and significant at $5 \% ;++(--)$ at $10 \% ;+(-)$ at $15 \%$.

Table 6: Variance decomposition

\begin{tabular}{|l|cccccc|}
\hline & $\begin{array}{c}\text { Localiz } \\
\text { variance }\end{array}$ & $\begin{array}{c}\text { Urbaniz } \\
\text { variance }\end{array}$ & $\begin{array}{c}\text { Geogr } \\
\text { variance }\end{array}$ & $\begin{array}{c}\text { Localiz, Urbaniz } \\
\text { covariance }\end{array}$ & $\begin{array}{c}\text { Localiz, Geog } \\
\text { covariance }\end{array}$ & $\begin{array}{c}\text { Urbaniz, Geog } \\
\text { covariance }\end{array}$ \\
\hline Farming & 1.86 & 1.12 & 0.36 & $-1.86 \mathrm{E}-04$ & $-6.33 \mathrm{E}-05$ & $4.08 \mathrm{E}-05$ \\
Ag services & 1.61 & 0.78 & 0.09 & $-3.43 \mathrm{E}-04$ & $-9.96 \mathrm{E}-06$ & $-4.14 \mathrm{E}-05$ \\
Mining & 2.02 & 0.93 & 0.21 & $-1.15 \mathrm{E}-03$ & $1.06 \mathrm{E}-04$ & $-1.83 \mathrm{E}-04$ \\
Construction & 4.64 & 5.11 & 0.31 & $-7.88 \mathrm{E}-04$ & $5.93 \mathrm{E}-05$ & $-6.91 \mathrm{E}-05$ \\
Manufacturing & 1.08 & 0.26 & 0.08 & $-1.18 \mathrm{E}-04$ & $4.63 \mathrm{E}-05$ & $-2.57 \mathrm{E}-05$ \\
Transp/util & 0.98 & 0.21 & 0.08 & $-4.15 \mathrm{E}-05$ & $5.46 \mathrm{E}-06$ & $-1.13 \mathrm{E}-05$ \\
Wholesale & 1.13 & 0.28 & 0.08 & $-1.35 \mathrm{E}-04$ & $1.90 \mathrm{E}-05$ & $-3.33 \mathrm{E}-05$ \\
Retail & 2.22 & 2.68 & 0.56 & $-2.39 \mathrm{E}-04$ & $6.39 \mathrm{E}-06$ & $-5.82 \mathrm{E}-06$ \\
FIRE & 1.97 & 2.03 & 0.49 & $-2.13 \mathrm{E}-04$ & $2.21 \mathrm{E}-05$ & $-2.35 \mathrm{E}-05$ \\
Other services & 0.68 & 0.79 & 0.36 & $-3.20 \mathrm{E}-05$ & $6.50 \mathrm{E}-06$ & $-7.33 \mathrm{E}-06$ \\
Fed civ & 1.28 & 0.67 & 0.22 & $-1.11 \mathrm{E}-04$ & $1.40 \mathrm{E}-05$ & $-1.64 \mathrm{E}-05$ \\
Military & 1.94 & 2.34 & 0.30 & $-1.69 \mathrm{E}-04$ & $1.73 \mathrm{E}-06$ & $-7.88 \mathrm{E}-06$ \\
State/Local & 0.51 & 0.58 & 0.82 & $-4.15 \mathrm{E}-05$ & $4.51 \mathrm{E}-06$ & $-7.48 \mathrm{E}-06$ \\
\hline
\end{tabular}


Table 7: $R^{2}$ s for different regressions

\begin{tabular}{|l|cccc|}
\hline & Total & Localization & Urbanization & Geography \\
\hline Farming & 0.2828 & 0.0869 & 0.04 & 0.0601 \\
Ag services & 0.3698 & 0.2731 & 0.0307 & 0.0187 \\
Mining & 0.2835 & 0.2109 & 0.0334 & 0.0384 \\
Construction & 0.1674 & 0.0471 & 0.031 & 0.0384 \\
Manufacturing & 0.2736 & 0.2358 & 0.0551 & 0.0537 \\
Transp/util & 0.2945 & 0.2638 & 0.0206 & 0.0342 \\
Wholesale & 0.3581 & 0.3058 & 0.029 & 0.0188 \\
Retail & 0.1311 & 0.0209 & 0.0455 & 0.0856 \\
FIRE & 0.1303 & 0.0441 & 0.0167 & 0.061 \\
Other services & 0.0955 & 0.0298 & 0.0352 & 0.0406 \\
Fed civ & 0.2237 & 0.1681 & 0.0083 & 0.0516 \\
Military & 0.1257 & 0.0608 & 0.0265 & 0.0355 \\
State/Local & 0.2134 & 0.0428 & 0.0148 & 0.1679 \\
\hline
\end{tabular}

